ARTICLE

DOI: $10.1038 / \mathrm{s} 41467-017-01477-5$

\title{
Critical functions for STAT5 tetramers in the maturation and survival of natural killer cells
}

\author{
Jian-Xin Lin', Ning Du ${ }^{1}$, Peng Li ${ }^{1}$, Majid Kazemian (1) ${ }^{1,2}$, Tesfay Gebregiorgis ${ }^{1}$, Rosanne Spolski ${ }^{1}$ \\ \& Warren J. Leonard ${ }^{1}$
}

Interleukin-15 (IL-15) is essential for the development and maintenance of natural killer (NK) cells. IL-15 activates STAT5 proteins, which can form dimers or tetramers. We previously found that NK cell numbers are decreased in Stat5a-Stat5b tetramer-deficient double knockin (DKI) mice, but the mechanism was not investigated. Here we show that STAT5 dimers are sufficient for NK cell development, whereas STAT5 tetramers mediate NK cell maturation and the expression of maturation-associated genes. Unlike the defective proliferation of Stat5 DKI CD8 ${ }^{+}$T cells, Stat5 DKI NK cells have normal proliferation to IL-15 but are susceptible to death upon cytokine withdrawal, with lower $B c / 2$ and increased active caspases. These findings underscore the importance of STAT5 tetramers in maintaining NK cell homoeostasis. Moreover, defective STAT5 tetramer formation could represent a cause of NK cell immunodeficiency, and interrupting STAT5 tetramer formation might serve to control NK leukaemia.

\footnotetext{
${ }^{1}$ Laboratory of Molecular Immunology and the Immunology Center, National Heart, Lung, and Blood Institute, National Institutes of Health, Bethesda, MD 20892-1674, USA. ²Present address: Department of Biochemistry and Computer Science, Purdue University, West Lafayette, IN 47906, USA. Jian-Xin Lin and Ning Du contributed equally to this work. Correspondence and requests for materials should be addressed to J.-X.L. (email: linjx@nhlbi.nih.gov) or to W.J.L. (email: wjl@helix.nih.gov)
} 
TAT5A and STAT5B are signal transducers and activators of transcription (STAT) family proteins ${ }^{1,2}$. These transcription factors are critical for the actions of many cytokines, including growth hormone, prolactin, erythropoietin, haematopoietic cytokines (such as IL-3, IL-5 and GM-CSF) and immune cytokines (such as IL-2, IL-7, IL-9, IL-15 and TSLP) ${ }^{3}$. The formation of STAT5 dimers depends on bivalent interactions between a key C-terminal phosphotyrosine of each STAT5 monomer and the SH2-domain of the other monomer, allowing the STAT5 dimer binding to $\gamma$-interferon activated sequence (GAS) motifs ${ }^{1,2}$. Additionally, STAT5 proteins ${ }^{4,5}$, analogous to STAT1 and STAT $4^{6-8}$, can form tetramers by an N-terminal region ( $\mathrm{N}$-domain)-mediated interaction between two dimers, which allows binding to lower affinity tandemly linked non-consensus GAS motifs.

We have previously shown that mutant STAT5 proteins that cannot form tetramers are expressed at a similar level to WT STAT5 proteins and can be phosphorylated in response to IL-2 stimulation ${ }^{9}$. To determine the importance of STAT5 tetramerization in vivo, we also identified and mutated residues in the STAT5A and STAT5B N-domains that are critical for tetramerization and generated Stat5a and Stat5b single knockin and Stat $5 a /$ Stat $5 b$ double knockin (DKI) mice ${ }^{9}$. In marked contrast to the perinatal lethality observed in Stat $5 a /$ Stat $5 b$ double knockout a

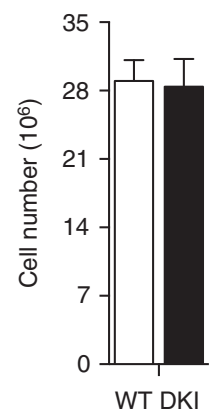

f

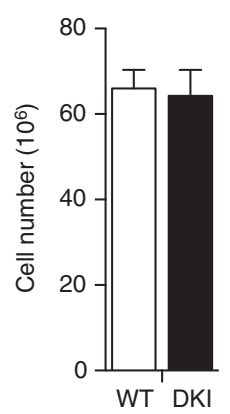

b
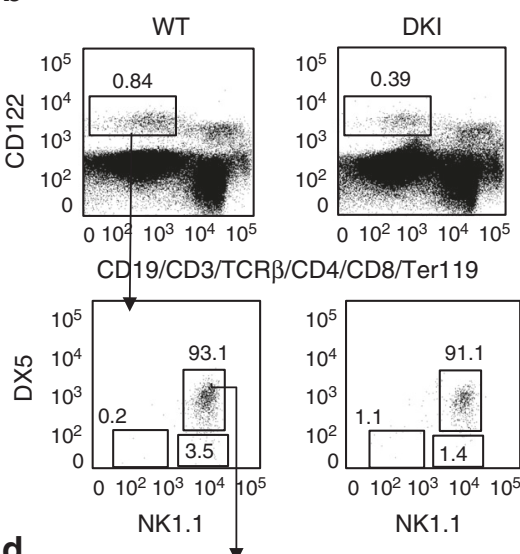

d

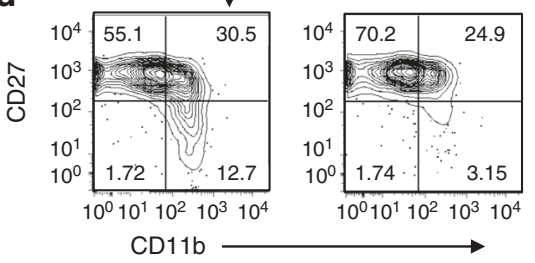

g $\quad \mathrm{W}$
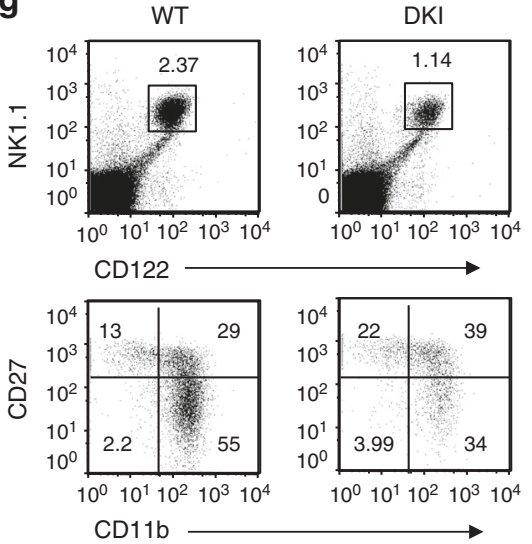

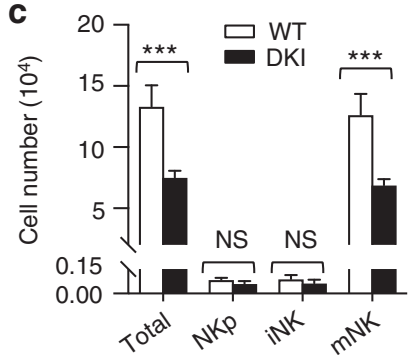

e

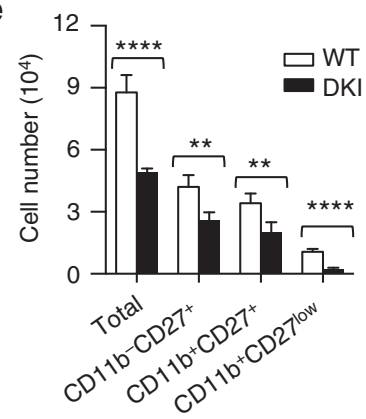

h

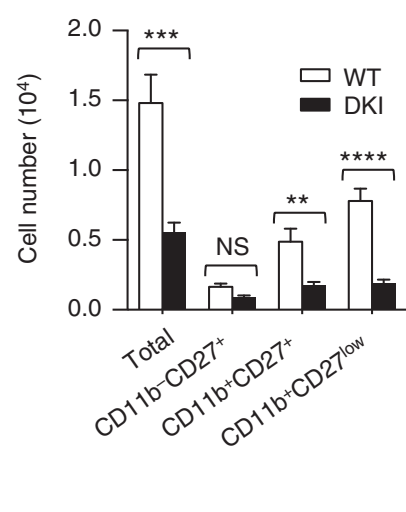

Fig. 1 Decreased bone marrow and splenic NK cells in Stat5 double knockin (DKI) mice. a Total bone marrow cell numbers from 8 WT (open bar) and 8 Stat5 DKI (filled bar) mice after removal of red blood cells. b Representative flow cytometric data of total bone marrow NK cells (lin(CD19, CD3, TCR $\beta$,

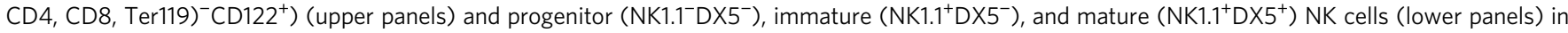
WT and Stat5 DKI (DKI) bone marrow. The numbers are the percentage of gated populations. c Total bone marrow NK (Total), NK progenitor (NKp), immature NK (iNK) and mature NK (mNK) cell numbers from 8 WT (open bars) or 8 DKI (filled bars) mice. d Representative flow cytometric data of total bone marrow NK cells from WT and Stat5 DKI mice gated as $\operatorname{lin}^{-} \mathrm{CD} 122^{+} \mathrm{NK} 1.1^{+} \mathrm{DX} 5^{+}$(lower panels of $\mathbf{b}$ ) and further characterised based on CD11b and CD27 staining. e Numbers of total bone marrow NK cells (Total) and CD11b $\mathrm{b}^{-} \mathrm{CD} 7^{+}, \mathrm{CD} 11 \mathrm{~b}^{+} \mathrm{CD} 27^{+}$, and $\mathrm{CD} 11^{+} \mathrm{CD} 27^{\text {low }}$ populations from 8 WT (open bars) and 8 Stat5 DKI (filled bars) mice. $\mathbf{f}$ Total splenocyte numbers from 8 WT (open bar) and 8 Stat5 DKI (filled bar) mice, after removing red blood cells. g Representative flow cytometric data of total splenic NK cells from WT and Stat5 DKI mice gated as $\mathrm{CD}^{-} \mathrm{CD} 122^{+} \mathrm{NK} 1.1^{+}$(upper panels) and further characterised based on CD11b and CD27 staining (lower panels). h Number of total splenic NK cells (Total), CD11b ${ }^{-}$CD27 ${ }^{+}, C^{2} 11 b^{+} C D 27^{+}$, and $C D 11$ ${ }^{+} \mathrm{CD} 27^{\text {low }}$ populations from $8 \mathrm{WT}$ (open bars) and $8 \mathrm{DKI}$ (filled bars) mice. Error bars in $\mathbf{c}$, e and $\mathbf{h}$ are means \pm SEM and statistical analyses were performed by grouped multiple $t$-test using Prism $7.0 \mathrm{~b}$ 
a

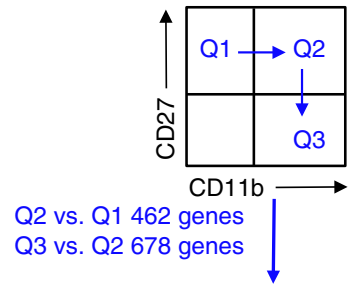

Differential expression during WT NK cell maturation (892 total genes as some are differentially expressed in both $\mathrm{Q}$ to $\mathrm{Q} 2$ and $\mathrm{Q} 2$ to $\mathrm{Q}$ ) b
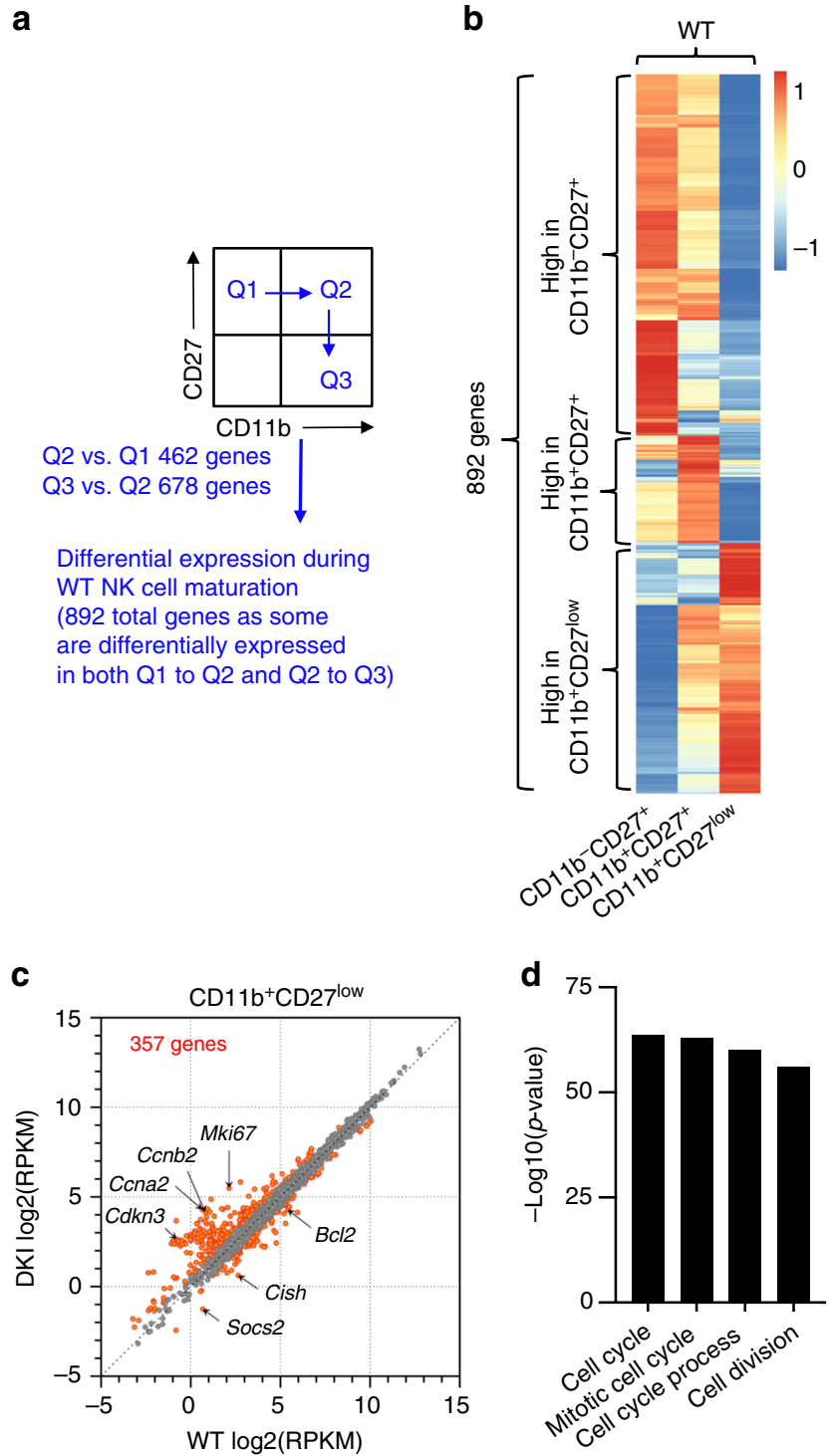
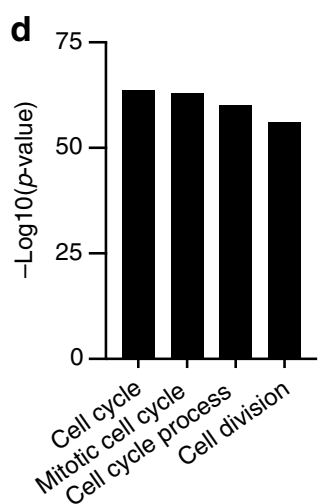

Fig. 2 Altered gene expression in Stat5 double knockin (DKI) NK cells. a Schematic illustration of NK maturation; we identified genes differentially regulated between $\mathrm{Q} 1$ to $\mathrm{Q} 2$ and $\mathrm{Q} 2$ to $\mathrm{Q} 3$ in $\mathrm{WT}$ NK cells, where $\mathrm{Q} 1=$

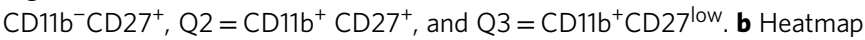
showing differentially expressed genes in WT NK subpopulations, as illustrated in a. Genes expressed higher in each WT subpopulation were indicated by black curly brackets on the left. The heatmap colours in each row are proportional to RPKM values. c Scatter plot showing all genes in grey and differentially expressed genes in red between WT and Stat5 DKI $\mathrm{CD}_{11 b^{-}} \mathrm{CD} 27^{\text {low }} \mathrm{NK}$ cells. d Bar graph showing the 4 gene sets most enriched in the gene list of $\mathbf{c}$ based on the Gene Set Enrichment Analysis algorithm (GSEA, Broad Institute, Boston, MA)

mice ${ }^{10}$, STAT5 tetramer-deficient DKI mice survive and develop normally ${ }^{9}$. However, these mice have fewer $\mathrm{CD} 8^{+} \mathrm{T}$ cells, and have defective $\mathrm{CD} 8^{+} \mathrm{T}$-cell proliferation in vitro, as well as in response to acute infection with lymphocytic choriomeningitis virus (LCMV) in vivo ${ }^{9}$. $\mathrm{CD} 4^{+} \mathrm{CD} 25^{+}$cells were also diminished in number in Stat5 DKI mice, with attenuated regulatory $\mathrm{T}$ (Treg) cell function in a model of inflammatory bowel disease ${ }^{9}$. In addition to these $\mathrm{T}$ cell defects, we also observed decreased numbers of splenic natural killer (NK) cells, but the basis for this defect and the functional activity of Stat5 DKI NK cells was not explored.
NK cells are vital to innate immunity through their cytolytic activity and ability to eliminate tumour cells and pathogen-infected cells ${ }^{11-15}$, and also contribute to adaptive immune responses, particularly through their production of pro-inflammatory (TNF and IFN $\gamma$ ) and immunosuppressive (IL-10) cytokines as well as chemokines ${ }^{13,16}$. Conventional NK cells develop and mature in the bone marrow, where IL-15 promotes their differentiation, maturation, survival and expansion $^{11,17}$. IL-15 binds with high affinity to the IL-15 receptor $\alpha$ chain (IL-15R $\alpha)^{18}$ and signals primarily via its transpresentation ${ }^{19,20}$ by IL-15R $\alpha$ to a heterodimer consisting of the IL- 2 receptor $\beta$ chain (IL-2R $\beta$ ) and common cytokine receptor $\gamma$ chain $\left(\gamma_{c}\right)^{21,22}$, although cis signalling can also occur when all three receptor chains are co-expressed ${ }^{23}$. The essential functions of IL-15 signalling in the development, maturation, survival and expansion of NK cells are underscored by the findings that deletion of either $I l 15^{24}$ or $I l 15 r a^{25}$ causes profoundly defective NK-cell development. Interestingly, mice lacking $I l 15^{24}$ have fewer NK cells than mice lacking $I 115 \mathrm{ra}^{25}$, consistent with the ability of IL-15 to signal via either IL-2R $\beta / \gamma_{c}$ dimeric or IL-15R $\alpha / \mathrm{IL}-2 \mathrm{R} \beta / \gamma_{\mathrm{c}}$ trimeric receptor complexes on NK cells.

There are fewer NK cells in mice lacking either Stat5a or particularly $S t a t 5 b^{26}$, and mice lacking both Stat $5 a$ and Stat $5 b$ are essentially devoid of NK cells ${ }^{10}$. Because NK cells develop in Stat 5 DKI mice, albeit in decreased numbers, we could use these animals to investigate the biological actions of STAT5 tetramers and dimers in NK cell development and function. Whereas STAT5 dimers are sufficient for the early development of conventional NK cells and cytotoxicity, STAT5 tetramers are required for the later stages of maturation of conventional NK cells in bone marrow and spleen, and for the development of thymic NK cells. Interestingly, STAT5 tetramers are not required for NK cell expansion but are required for maintaining expression of anti-apoptotic proteins and suppression of pro-apoptotic proteins, and thus for NK cell survival. The decreased expression of BCL2 in Stat5 DKI NK cells is associated with increased levels of active caspases that initiate NK cell death. Our data thus reveal that both a partial block of NK maturation and increased NK cell death contribute to the lower NK cell numbers observed in Stat5 DKI mice, underscoring the critical functions of STAT5 tetramers in the maturation and survival of NK cells.

\section{Results}

STAT5 tetramers are required for normal NK cell numbers. To study the function of STAT5 tetramers in the development of conventional natural killer (NK) cells, we initially compared the maturation status of NK cells in bone marrow and spleen in WT and Stat5 DKI mice. The total numbers of WT and Stat5 DKI bone marrow cells were similar (Fig. 1a); however, in the Stat5 DKI mice, there was a $\sim 50 \%$ decrease in the frequency of bone marrow $\operatorname{lin}^{-} \mathrm{CD} 122^{+}$total NK cells (Fig. 1b, upper right versus upper left panel), without a significant change in the frequency of $\mathrm{NK} .1^{+} \mathrm{DX}^{+}$mature NK cells (Fig. 1b, lower panels), resulting in fewer total Stat5 DKI NK cells (Fig. 1c). The $\operatorname{lin}^{-} \mathrm{CD} 122^{+} \mathrm{NK} 1.1^{+} \mathrm{DX} 5^{+}$mature NK cells $(\mathrm{mNK})$ were substantially decreased, whereas $\operatorname{lin}^{-} \mathrm{CD} 122^{+} \mathrm{NK} 1.1^{-} \mathrm{DX} 5^{-}$ progenitor $\mathrm{NK}(\mathrm{NKp})$ and $\operatorname{lin}^{-} \mathrm{CD} 122^{+} \mathrm{NK} 1.1^{+} \mathrm{DX} 5^{-}$immature NK (iNK) cells were not significantly affected (Fig. 1c).

Based on cell surface expression of CD11b and CD27, mouse conventional NK cells can be further divided into four maturation subsets, from $\mathrm{CD} 11 \mathrm{~b}^{-} \mathrm{CD} 27^{-} \mathrm{NK}$ cells, through $\mathrm{CD} 11 \mathrm{~b}^{-} \mathrm{CD} 27^{+}$ and $\mathrm{CD}_{11 \mathrm{~b}^{+} \mathrm{CD} 27^{+}} \mathrm{NK}$ cells, to terminally differentiated $\mathrm{CD} 11 \mathrm{~b}^{+} \mathrm{CD} 27^{\text {low }}$ mature $\mathrm{NK}$ cells $\mathrm{s}^{27-29}$. In Stat5 DKI bone marrow, the frequency of terminally differentiated $\mathrm{CD} 11 \mathrm{~b}^{+} \mathrm{CD} 27^{\text {low }}$ mature $\mathrm{NK}$ cells was markedly decreased, 
whereas $\mathrm{CD}_{11 \mathrm{~b}}^{-} \mathrm{CD} 27^{+} \mathrm{NK}$ cells were increased (Fig. 1d), underscoring the importance of STAT5 tetramers for NK cell maturation beyond the $\mathrm{CD} 11^{-} \mathrm{CD} 27^{+}$stage. In fact, the number of each subpopulation of NK cells was decreased, but the defect was greatest in the most mature Stat5 DKI NK cells (Fig. 1e). Analogous to bone marrow, total splenocyte numbers were similar in WT and Stat5 DKI mice (Fig. 1f), but total NK cell frequency (Fig. 1g, upper panels) and numbers (Fig. 1h; ref. ${ }^{9}$ ) were lower in Stat5 DKI NK mice, with a partial block in maturation (Fig. 1g, lower panels), with the greatest defect in terminally differentiated $\mathrm{CD} 11 \mathrm{~b}^{+} \mathrm{CD} 27^{\text {low }} \mathrm{NK}$ cells (Fig. 1h).

Because IL-7 activates STAT5 proteins ${ }^{30}$ and thymus-derived NK cell homoeostasis depends on IL- $7^{31}$, we also examined thymic NK cells. The frequency of total $\left(\mathrm{lin}^{-} \mathrm{CD} 122^{+}\right)$thymic NK cells was moderately decreased in Stat5 DKI mice (Supplemantary Fig. 1a, upper panels), whereas the frequency of mature $\left(\mathrm{CD} 122^{+} \mathrm{NK} 1.1^{+} \mathrm{DX} 5^{+}\right)$thymic $\mathrm{NK}$ cells showed little if any decrease (Supplementary Fig. 1a, lower panels). Nevertheless, the number of these cells was significantly lower in Stat5 DKI than in WT mice (Grouped Multiple $t$-test, $p<0.001$, Supplementary Fig. 1b). IL-7R $\alpha$ expression was normal (Supplementary Fig. 1c, d), so we attribute the decrease in thymic NK cell numbers to defective STAT5 tetramer formation. Thus, STAT5 tetramers are essential for the maintenance and/or expansion of thymic as well as bone marrow and splenic NK cells.

STAT5 tetramers mediate NK cell-related gene expression. Because mature $\mathrm{CD} 11 \mathrm{~b}^{+} \mathrm{CD} 27^{\text {low }} \mathrm{NK}$ cells were significantly reduced in Stat5 DKI bone marrow and spleen, we next performed RNA-Seq using sorted splenic NK cells to identify the genes whose expression correlated with the $\mathrm{CD} 11 \mathrm{~b}^{-} \mathrm{CD} 27^{+}$to $\mathrm{CD}_{11 \mathrm{~b}}{ }^{+} \mathrm{CD} 27^{+}(\mathrm{Q} 1-\mathrm{Q} 2)$ and $\mathrm{CD} 11 \mathrm{~b}^{+} \mathrm{CD} 27^{+}$to $\mathrm{CD} 11 \mathrm{~b}^{+} \mathrm{CD} 27^{\text {low }}$ (Q2 to Q3) transitions (as illustrated in Fig. 2a). First, we compared expression profiles in these populations of WT NK cells (purity of sorted NK populations ranged from 92 to $100 \%$, Supplementary Fig. 2a, b) and identified a total of 892 genes that were differentially expressed during these transitions (Reads Per Kilobase of transcript per Million mapped reads (RPKM) $\geq 5$ in at least one population and fold change $(\mathrm{FC}) \geq 1.5$ )(Fig. 2a, b, Supplementary Data 1a). Of these, 462 genes were differentially expressed during the $\mathrm{CD} 11 \mathrm{~b}^{-} \mathrm{CD} 27^{+}$to $\mathrm{CD} 11 \mathrm{~b}^{+} \mathrm{CD} 27^{+}$transition and 678 genes during the $\mathrm{CD} 11 \mathrm{~b}^{+} \mathrm{CD} 27^{+}$to $\mathrm{CD} 11 \mathrm{~b}^{+} \mathrm{CD} 27^{\text {low }}$ transition, with some (248 genes) differentially expressed in both transitions (Fig. 2a, Supplementary Data 1b, c). These included 82 genes encoding transcription factors (TFs) (Supplementary Fig. 2c, Supplementary Data 1f) such as Tox, Klf4, and Prdm1 (Supplementary Fig. 2c, d) and 77 genes encoding cytokines, chemokines, their receptors, and NK receptors such as inhibitory NK receptor Klrg1, activating NK receptor Cd160, and $I l 7 r$ (Supplementary Fig. 2e, f, Supplementary Data 1g).

Interestingly, a number of genes encoding transcription factors (Supplementary Fig. 2c) and cytokines/chemokines/receptors/NK receptors (Supplementary Fig. 2e) had altered expression in Stat5 DKI NK subpopulations as compared to cells from WT mice (Supplementary Fig. 3a-f, respectively); whether they are responsible for the maturation defects seen in Stat5 DKI NK cells remains to be elucidated.

Most of the 892 genes that were differentially expressed during the $\mathrm{CD} 11 \mathrm{~b}^{-} \mathrm{CD} 27^{+}$to $\mathrm{CD} 11 \mathrm{~b}^{+} \mathrm{CD} 27^{+}$and/or $\mathrm{CD} 11 \mathrm{~b}^{+} \mathrm{CD} 27^{+}$to $\mathrm{CD} 11 \mathrm{~b}^{+} \mathrm{CD} 27^{\text {low }}$ transitions had similar expression patterns in corresponding WT and Stat5 DKI NK populations, but some genes, including those encoding a number of cytokine signalling molecules (e.g., Cish and Socs2) and anti-apoptotic protein (Bcl2) were expressed at lower levels in Stat5 DKI NK cells (Fig. 2c). Interestingly, a number of genes, including some of those involved in cell cycle progression, were downregulated during the

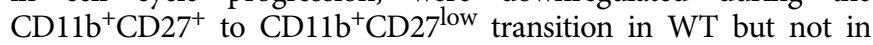
Stat5 DKI NK cells. For example, Mki67, Ccna2, Ccnb2 and Cdkn3 were still expressed at higher levels in Stat5 DKI CD $11 \mathrm{~b}^{+} \mathrm{CD} 27^{\text {low }}$ NK cells than those in corresponding WT NK cells (Fig. 2c and Supplementary Data 1d). A Gene Set Enrichment Analysis of the 357 differentially expressed genes in WT versus Stat5 DKI CD11 ${ }^{+} \mathrm{CD} 27^{\text {low }} \mathrm{NK}$ cells revealed that the top 4 enriched gene sets are involved in cell cycle progression (Fig. 2d). Surprisingly, most of the genes (e.g., Il2rb, Il2rg, Il15ra, Il7r, Stat5a, Stat5b, Jak3, Eomes, Elf4, Ets1, Ets2, Nfil3, Gata3, Id2, Irf1, Irf2, Klf4, Prdm1, Tbx21 and Tox) (Supplementary Fig. 4a) known to be critical for NK development and/or maturation $24,26,32-44$ were similarly expressed in $\mathrm{CD}_{11} \mathrm{~b}^{-} \mathrm{CD} 27^{+}$(Supplementary Fig. 4b), CD11b ${ }^{+} \mathrm{CD} 27^{+}$(Supple-

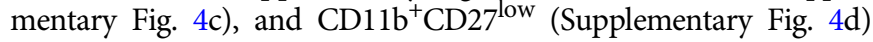
subpopulations of WT and Stat5 DKI NK cells (Supplementary Data 1e). Expression of the genes encoding JAK1, JAK2 and JAK3 and all seven STAT proteins was similar in $\mathrm{CD}_{11 \mathrm{~b}}^{-} \mathrm{CD} 27^{+}$ (Supplementary Fig. 4e), CD $11 b^{+} \mathrm{CD} 27^{+}$(Supplementary Fig. 4f), and $\mathrm{CD} 11 \mathrm{~b}^{+} \mathrm{CD} 27^{\mathrm{low}}$ (Supplementary Fig. 4g) WT and Stat5 DKI NK cells (Supplementary Data 1e).

STAT5 tetramers are needed for cytokine-mediated NK survival. As noted above, there are fewer NK cells in Stat5 DKI mice (Fig. 1h; Supplementary Fig. 2a). To evaluate their functionality, we expanded both WT and Stat5 DKI splenic NK cells with IL-15 in vitro (Supplementary Fig. 3a) and found that both populations exhibited similar killing of ${ }^{51}$ Cr-labelled YAC-1 cells (Fig. 3a). Moreover, WT and Stat5 DKI mice showed similar clearance of $\mathrm{H} 2$ class I gene-deficient RMA-S T lymphoma cells ${ }^{45}$ (Fig. 3b, c). No statistically significant difference between WT and Stat5 DKI mice was observed in RMA-S tumour rejection experiments (Kaplan-Meier method, $p=0.323$ ), although Stat5 DKI mice appeared slightly less efficient in rejecting RMA-S tumour cells in vivo (Fig. 3d). These experiments together showed that despite there being fewer NK cells in the Stat5 DKI mice, their cytotoxicity was normal, indicating that STAT5 dimers are sufficient for this function.

Because STAT5 tetramers are essential for normal IL-2- and IL-15-induced proliferation of $\mathrm{CD}^{+} \mathrm{T}$ cells in vitro and homoeostatic proliferation of these cells in vivo ${ }^{9}$, we next investigated whether the decreased NK cell numbers in Stat5 DKI mice might result from defective proliferation. Unexpectedly, Stat5 DKI bone marrow (Fig. 3e, f) and splenic (Fig. 3g, h) NK cells had similar or even slightly higher proliferation to IL-15 (Fig. 3e, g) or IL-2 (Fig. 3f, h). These results were consistent with a slightly higher percentage of $\mathrm{Ki}^{+} 7^{+}$Stat5 DKI NK cells among freshly isolated and IL-15-stimulated bone marrow (Fig. 3i) or splenic (Fig. 3j) NK cells. Moreover, when cultured in vitro with IL-15 (Fig. 3k) or IL-2 (Fig. 31), there were fewer viable Stat5 DKI than WT splenic NK cells, particularly at low concentrations of the cytokines, indicating defective cytokine-induced survival of the Stat5 DKI NK cells.

In view of the defective survival, we next examined whether there were differences in IL-15-induced gene expression by RNASeq. Of 467 genes that were most differentially expressed in either WT or Stat5 DKI NK cells after $24 \mathrm{~h}$ of stimulation with IL-15 (RPKM $\geq 5$, FC $\geq 2$; Supplementary Fig. 5b, Supplementary Data 2a), 71 genes had significantly altered expression in Stat5 DKI versus WT NK cells (Supplementary Fig. 5c, Supplementary Data 2b). Interestingly, Ccnd1 (encoding cylin D1) was dramatically increased in response to IL-15 stimulation in Stat5 DKI NK cells but not in WT NK cells (Supplementary Fig. 5c, d, Supplementary Data 2b). The expression of Cdkn2b (encoding p15 1 NK4B, which forms complexes with CDK4 and CDK6 and 

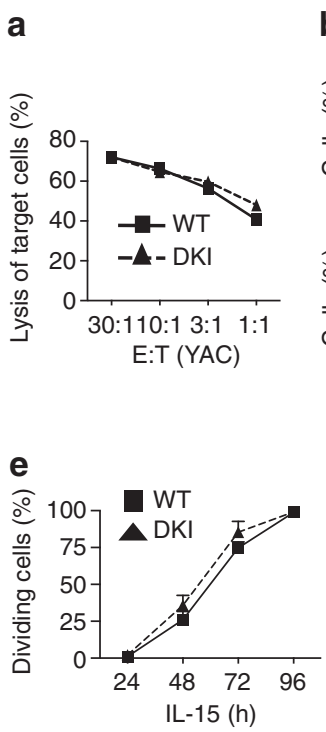

b

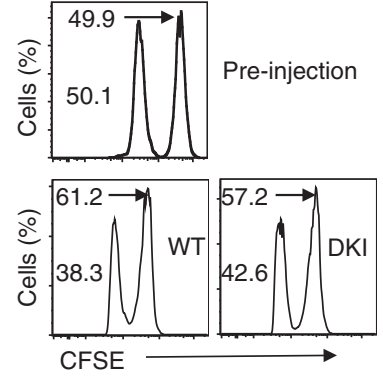

C

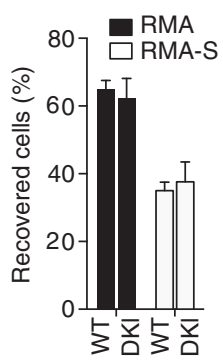

d

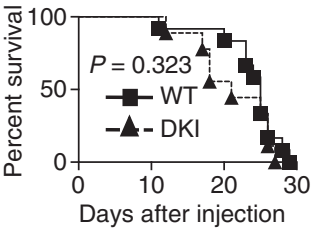

f

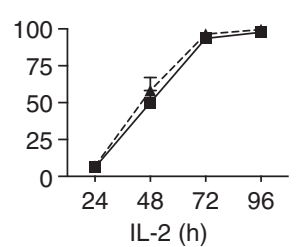

g

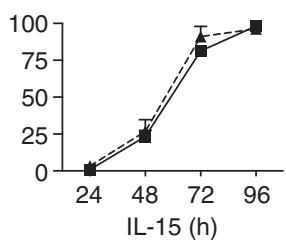

h

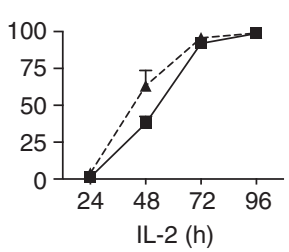

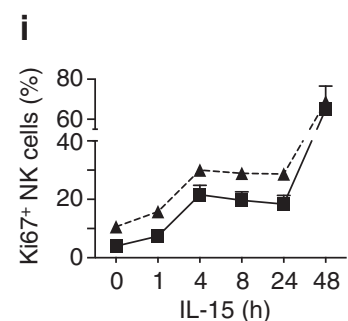

j

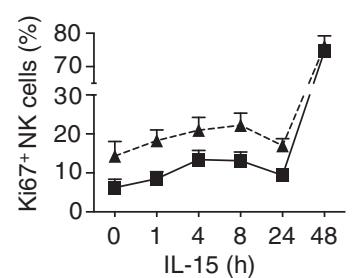

$\mathbf{k}$

|
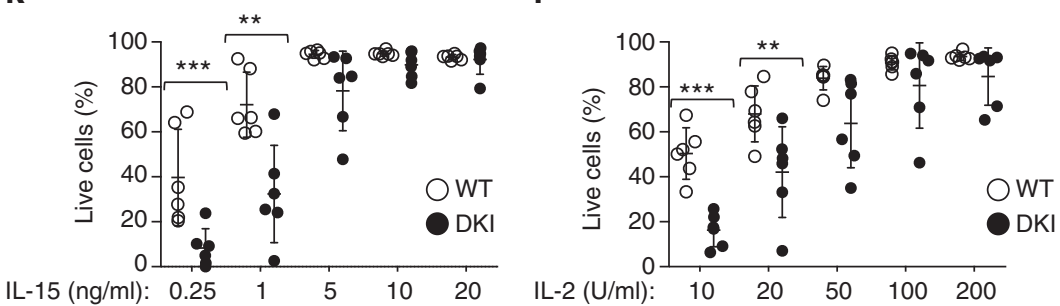

Fig. 3 Stat5 DKI NK cells have normal NK cytotoxicity and proliferative responses but defective survival in response to IL-2 and IL-15 stimulation. a Representative line graph showing the percentage of ${ }^{51} \mathrm{Cr}$-labelled YAC-1 cell lysis by WT (black squares and black lines) and Stat5 DKI (black triangles and dashed lines) NK cells. NK cells were isolated from three WT and Stat5 DKI mice. The experiment was performed twice. b Representative histograms showing percentage of CFSE-labelled RMA-S (first (left) peaks) and CFSE-labelled RMA (second (right) peaks) cells pre-injection or $16 \mathrm{~h}$ after intraperitoneal injection into WT and Stat5 DKI mice. The numbers indicate the percentage of RMA-S and RMA cells recovered. c Summary of two independent experiments. d Kaplan-Meier curves showing similar RMA-S tumour rejection in WT ( $n=12$, solid squares with line) and Stat5 DKI ( $n=9$, solid triangles with dotted line) mice. The data are derived from three independent experiments and the $p$-value (Mantel-Cox test) is shown. Black squares and solid lines indicate WT cells and black triangles and dotted lines indicate Stat5 DKI cells. e Time course of proliferative responses of WT and Stat5 DKI bone marrow NK cells in response to $20 \mathrm{ng} \mathrm{ml}^{-1} \mathrm{IL}-15$. Black squares and solid lines indicate WT cells and black triangles and dotted lines indicate Stat5 DKI cells. $\mathbf{f}$ Time course of proliferative responses of WT and Stat5 DKI bone marrow NK cells in response to $1000 \mathrm{U} \mathrm{ml} \mathrm{l}^{-1} \mathrm{IL}-2$. Black squares and solid lines indicate WT cells and black triangles and dotted lines indicate Stat5 DKI cells. $\mathbf{g}$ Time course of proliferative responses of WT and Stat5 DKI splenic NK cells in response to $20 \mathrm{ng} \mathrm{ml}^{-1} \mathrm{IL}-15$. Black squares and solid lines indicate WT cells and black triangles and dotted lines indicate Stat5 DKI cells. $\mathbf{h}$ Time course of proliferative responses of WT and Stat5 DKI splenic NK cells in response to $1000 \mathrm{U} \mathrm{ml}^{-1} \mathrm{IL}-2$. Black squares and solid lines indicate WT cells and black triangles and dotted lines indicate Stat5 DKI cells. i Line graphs of Ki67 staining of WT and DKI bone marrow NK cells stimulated with 20 ng ml ${ }^{-1}$ of IL-15 for 0, 1, 4, 8, 24 and 48 h, as indicated. Black squares and solid lines indicate WT cells and black triangles and dotted lines indicate Stat5 DKI cells. j Line graphs of Ki67 staining of WT and DKI splenic NK cells stimulated with $20 \mathrm{ng} \mathrm{ml}^{-1}$ of IL-15 for 0, 1, 4, 8, 24 and 48 h, as indicated. Black squares and solid lines indicate WT cells and black triangles and dotted lines indicate Stat5 DKI cells. (k and I) Dose response of WT (open circles) and Stat5 DKI (filled circles) splenic NK cells to IL-15 (k) or IL-2 (I) stimulation on day 4. The percentages of live cells were determined using live/dead cell assay kit and flow cytometry cell counting beads. Error bars in $\mathbf{c}$ and $\mathbf{e}-\mathbf{I}$ are means \pm SEM and statistical analyses were performed by grouped multiple $t$-test using Prism 7.0b 
a

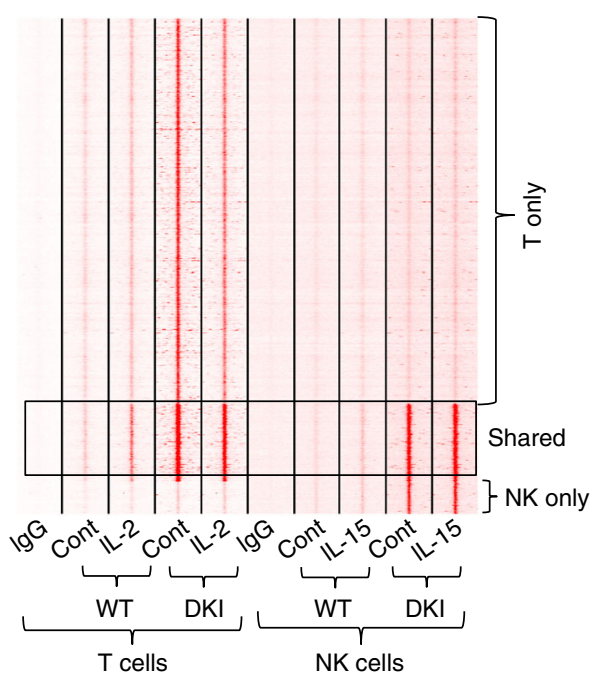

e

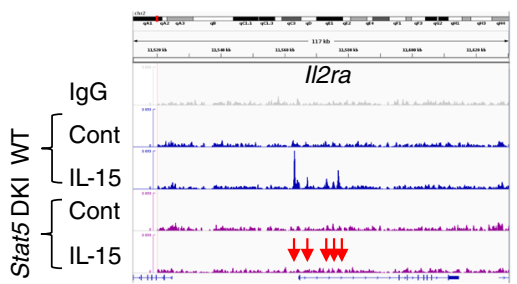

$\mathbf{f}$

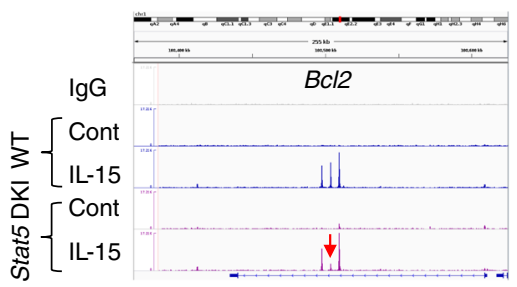

b

STAT5B binding sites

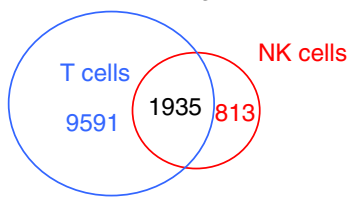

TCEAGA

Dimer motifs

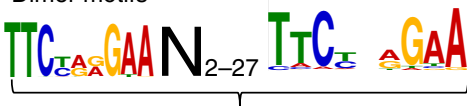

Tetramer motifs
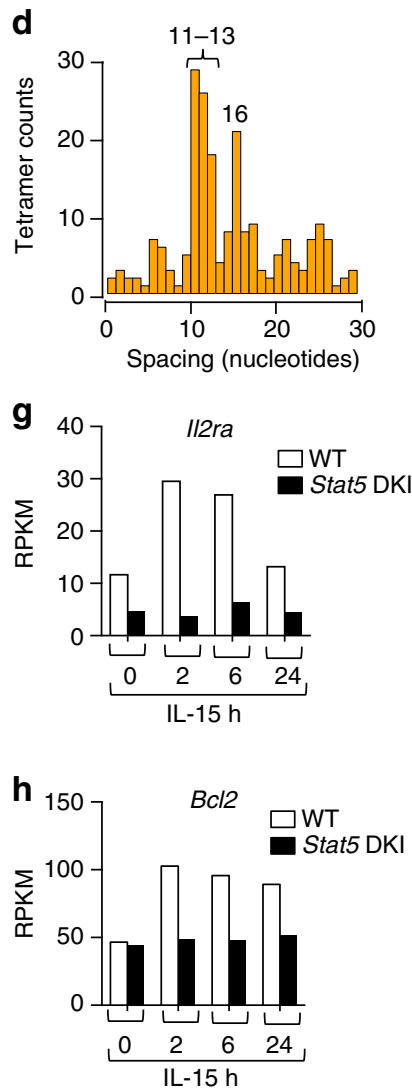

Fig. 4 Identification of STAT5 tetramer-regulated genes. $\mathbf{a}$, b Comparison of STAT5 binding sites in T and NK cells. a STAT5 binding sites only in T cells (T cell specific) or NK cells (NK-specific) are indicated on the right; STAT5 binding sites shared in both cells are in the black rectangle marked "Shared". b Venn diagram of 9591 T-cell specific STAT5 binding sites (blue), 813 NK-specific sites (red), and 1935 sites shared in T and NK cells (black). c STAT5 dimer (top) and tetramer (bottom) motifs identified in NK cells. The numbers indicate potential numbers of nucleotides between two tandemly linked tetramer binding sites shown in lower panel for STAT5 tetramer motifs. d Spacing distribution analysis between two tandemly linked tetramer binding sites; preferred spacings between two binding sites in tetramer motifs are marked (at 11-13, and 16 nucleotides). e STAT5 tetramer binding in the II2ra promoter and first intron. f STAT5 tetramer binding in the Bc/2 intronic region (red arrows). $\mathbf{g}$ IL-15 potently induces II2ra mRNAs in WT (open bars) but not in Stat5 DKI (black bars) NK cells. h IL-15 potently induces Bcl2 mRNAs in WT (open bars) but not in Stat5 DKI (black bars) NK cells

prevents CDK activation by cyclin D) was not regulated by IL-15 in WT NK cells but its level was significantly lower in Stat5 DKI NK cells and decreased further after IL-15 stimulation (Supplementary Fig. 5e). Conversely, Cish, an inhibitor of IL-15 signalling in $\mathrm{NK}$ cells ${ }^{46}$, had significantly lower expression in Stat5 DKI NK cells stimulated by IL-15 (Supplementary Fig. 5f). Higher cyclin but lower CDK inhibitor and Cish expression are consistent with Stat5 DKI NK cells exhibiting normal or even increased cell division in response to cytokine stimulation but does not explain the defective survival of these cells.
Bcl2 is regulated by STAT5 tetramers in NK cells. To clarify the mechanism underlying the defective survival of Stat5 DKI NK cells, we next sought to identify direct target genes for STAT5 dimers versus tetramers and thus performed ChIP-Seq using anti-STAT5B and WT or Stat5 DKI splenic NK cells expanded in vitro with IL-15. We identified 2748 STAT5 binding sites in IL-15-treated WT NK cells (Fig. 4a, b), far fewer than the 11,526 sites we observed in IL-2-treated T cells (Fig. 4a, b). Approximately $70 \%$ of the sites in NK cells (1935 of 2748 sites) were shared with those in $\mathrm{T}$ cells, while the rest were cell 

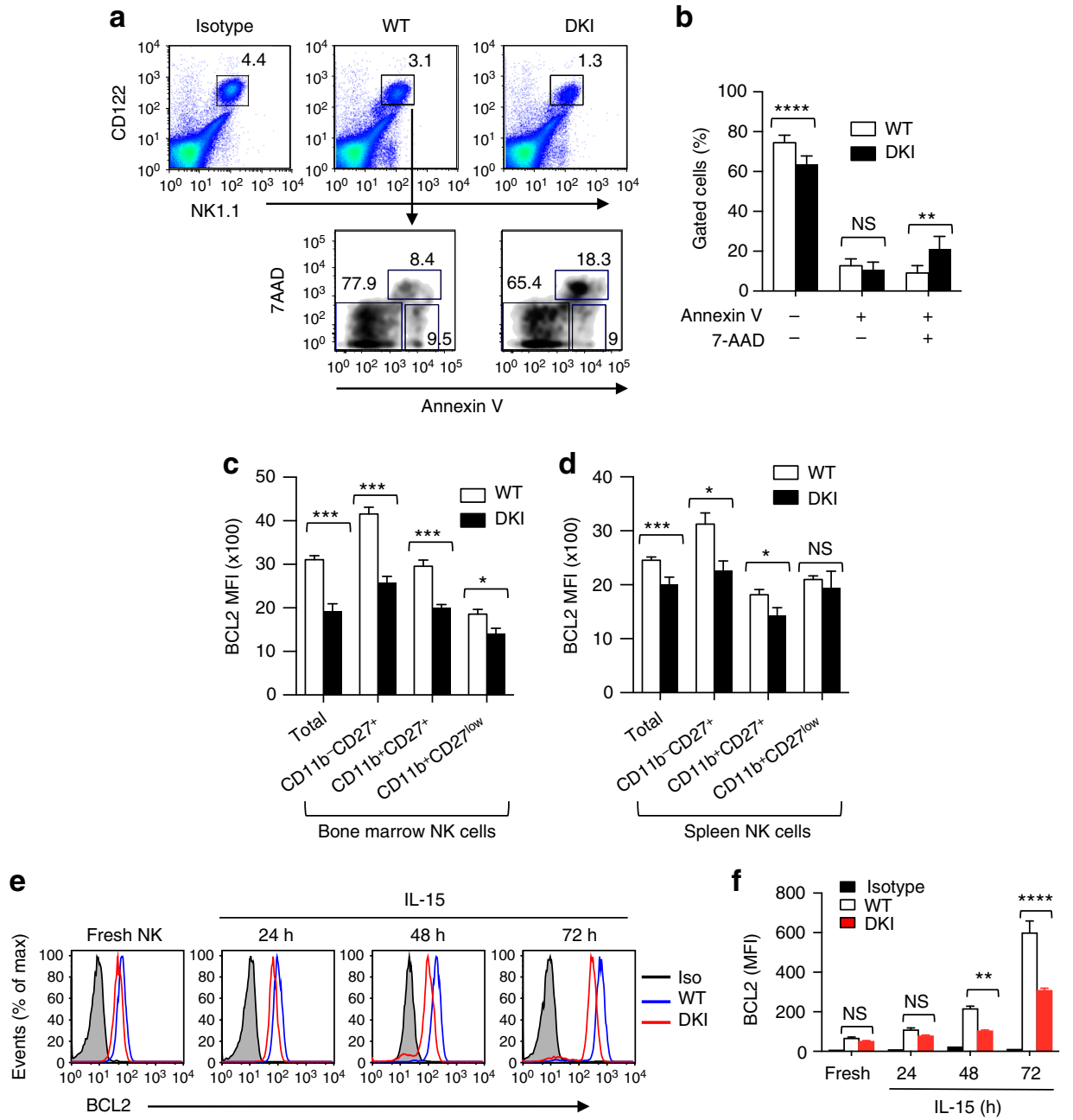

Fig. 5 Increased apoptosis and decreased BCL2 expression as well as increased cytokine withdrawal-induced cell death in Stat5 DKI NK cells. a, b Freshly isolated total spleen cells were stained with anti-CD3, anti-CD122, anti-NK1.1, Annexin $V$, and 7AAD. Apoptotic NK cells were identified as CD3 ${ }^{-} C D 122$ ${ }^{+} \mathrm{NK} 1.1^{+}$Annexin $\mathrm{V}^{+}$, and dead NK cells were identified as $\mathrm{CD} 3^{-} \mathrm{CD} 122^{+} \mathrm{NK} 1.1^{+}$Annexin $\mathrm{V}^{+} 7 \mathrm{AAD}{ }^{+}$(lower panels of $\mathbf{a}$ ). Percentages of apoptotic and dead cells in splenic NK cells from 7 WT (open bars) and 7 Stat5 DKI (filled bars) mice b. c, d BCL2 expression (MFI) of bone marrow (c) and spleen (d) NK cells. e Time course of BCL2 expression in splenic NK cells cultured with $20 \mathrm{ng} \mathrm{ml}^{-1} \mathrm{IL}-15 ; \mathrm{BCL} 2$ levels were determined by flow cytometry. Isotype control antibody (shaded in grey) and BCL2 antibody staining of WT (blue) and Stat5 DKI (red) NK cells are shown. $\mathbf{f}$ BCL2 expression levels (MFI) in IL-15-stimulated splenic NK cells from 3 WT (open bars) and 3 Stat5 DKI (red bars) mice. The experiment was performed twice. Error bars in $\mathbf{b}, \mathbf{c}$, $\mathbf{d}$ and f are means \pm SEM and statistical analyses were performed by grouped multiple $t$-test using Prism 7.0b

type-specific (Fig. 4a, b). By comparing the STAT5 binding sites identified in WT cells (bound by STAT5 dimers and/or tetramers) with those identified in Stat5 DKI cells (bound by STAT5 dimers but not tetramers), we identified 267 tetramer-specific binding sites; some genes had multiple sites, so these corresponded to a total 185 genes (Supplementary Data 3a). The motifs for both STAT5 dimers and tetramers (Fig. 4c) and the preferred spacing between two tandemly linked $\gamma$-interferon activated sequence (GAS) motifs in tetramer binding sites (Fig. 4d) were similar to what we defined in $\mathrm{T}$ cells ${ }^{9}$, although spacings of 11-13 and $16 \mathrm{bp}$ were even more preferred in NK cells $^{9}$ (Fig. 4d). Of the 185 genes associated with tetramer binding sites, a number of them had $\geq 1.5$-fold lower in mRNA expression in Stat5 DKI than WT NK cells, indicating that they were direct targets of STAT5 tetramers (Supplementary Data 3b). These included the known STAT5 tetramer-dependent Il2ra gene, but also $B c l 2$. STAT5 binding intensity to all of the sites in the Il2ra gene and to one of three intronic regions of $\mathrm{Bcl} 2$ gene were significantly reduced in Stat5 DKI cells stimulated by IL-15 (Fig. 4e, f). Consistent with the defective STAT5 tetramer binding, Il2ra and Bcl2 mRNAs were induced by IL-15 in WT NK cells but not in Stat5 DKI NK cells (Fig. 4g, h).

Rapid cytokine depletion-induced death of Stat5 DKI NK cells. The role of STAT5 tetramers in Bcl2 regulation and the diminished viability of Stat5 DKI NK cells cultured with lower doses of IL-2 or IL-15 led us to further examine the viability of freshly isolated NK cells (Fig. 5a, upper panels). There was a significant increase in Annexin $\mathrm{V}^{+} 7 \mathrm{AAD}^{+}$(Grouped Multiple $t$-test, $p<0.01)$ but not in the Annexin $\mathrm{V}^{+} 7 \mathrm{AAD}^{-}$cells among freshly isolated splenic Stat5 DKI NK cells as compared to WT NK cells (Fig. 5a, lower panels and Fig. 5b), consistent with the lower viability in the Stat5 DKI NK cells. Corresponding to our RNA-Seq analysis showing significantly decreased Bcl2 mRNA in Stat5 DKI NK cells (Fig. 4h), BCL2 protein levels were also significantly lower in freshly isolated bone marrow (Grouped Multiple $t$-test, $p<0.001$, Fig. $5 c$ ) and splenic (Grouped Multiple $t$-test, $p<0.001$, Fig. 5d) Stat5 DKI NK cells than in corresponding WT NK cells, and Bcl2 mRNA (Fig. 4h, Supplementary 

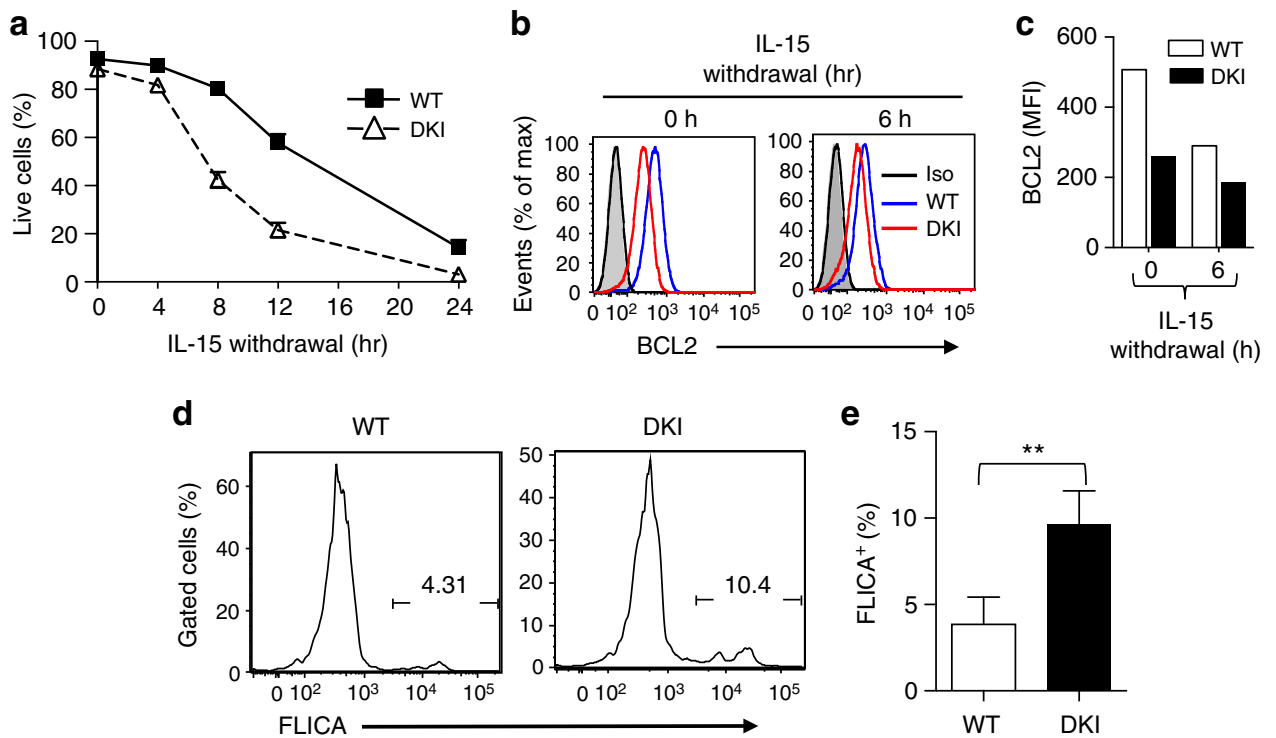

f

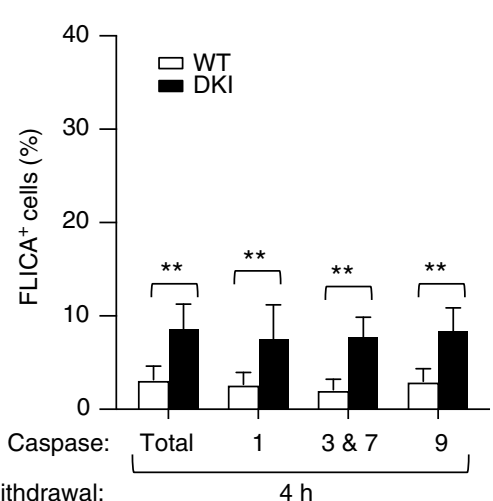

g

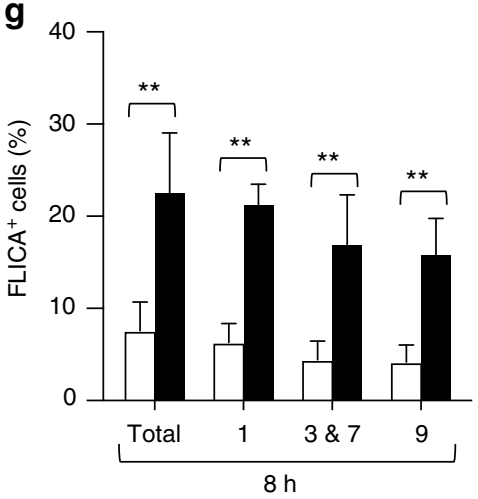

Fig. 6 Dysregulated expression of cell survival-related genes and increased active caspase levels in Stat5 DKI NK cells. a Time course of the percentage of viable WT (filled squares) or Stat5 DKI (open triangles) NK cells following IL-15 withdrawal. Cells were isolated from spleen and cultured in vitro with IL-15 for 6 days prior to withdrawal. Three WT and Stat5 DKI mice were used. The experiment was performed twice. Error bars are means \pm SEM and statistical analyses were performed by grouped multiple t-test using Prism 7.0b. b Histograms of intracellular BCL2 staining of WT (blue) and Stat5 DKI (red) NK cells. Staining was of cells cultured in $20 \mathrm{ng} \mathrm{ml}^{-1} \mathrm{IL}-15(\mathrm{O} \mathrm{h})$ or $6 \mathrm{~h}$ upon IL-15 withdrawal. c Summary of BCL2 levels (MFI) before (0 h) and after IL-15

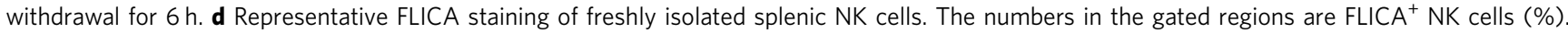
e Summary of $\mathbf{d}$ of freshly isolated splenic WT (open bar) and Stat5 DKI NK (filled bar) cells analysed using the FLICA Poly Caspase Assay kit. Error bars are means \pm SEM and statistical analyses were performed by grouped multiple $t$-test using Prism 7.0b. f Summary of FLICA staining of WT (open bars) and Stat5 DKI (closed bars) NK cells at $4 \mathrm{~h}$ after IL-15 withdrawal for poly caspases (Total), caspase-1 (1), caspases-3 and 7 (3, 7), and caspase-9. Error bars are means \pm SEM and statistical analyses were performed by grouped multiple $t$-test using Prism 7.0b. g Summary of FLICA staining of WT (open bars) and Stat5 DKI (closed bars) NK cells at $8 \mathrm{~h}$ after IL-15 withdrawal for poly caspases (Total), caspase-1 (1), caspases-3, 7 (3, 7), and caspase-9. Error bars are means \pm SEM and statistical analyses were performed by grouped multiple $t$-test using Prism $7.0 \mathrm{~b}$

Data $2 \mathrm{a}$ ) and BCL2 protein (Fig. 5e, f) were less potently induced by IL-15 in Stat5 DKI NK cells than in WT NK cells.

The lower induction of Bcl2 expression in the Stat5 DKI NK cells prompted us to evaluate the effect of IL-15 withdrawal. Importantly, Stat5 DKI NK cells that were expanded in vitro with IL-15 exhibited significantly more rapid cell death than we observed with similarly treated WT NK cells (Fig. 6a). BCL2 protein levels (Fig. 6b, c) also were lower in Stat5 DKI than in WT NK cells after IL-15 withdrawal, consistent with the increased apoptosis of Stat5 DKI NK cells and elucidating the basis for the lower number of NK cells in Stat5 DKI mice. Because BCL2 supports cellular viability and decreasing its expression can initiate an apoptotic cascade by activating caspases and eventually leading to cell death ${ }^{47,48}$, we hypothesised that decreased expression of anti-apoptotic factors rather than the induction of pro-apoptotic protein(s) was the basis for increased
NK cell death in the Stat5 DKI mice. We next assessed active caspase levels using the fluorochrome-labelled inhibitors of caspases (FLICA) assay and found significantly increased FLICA $^{+}$cells in freshly isolated splenic Stat5 DKI NK cells (Grouped Multiple $t$-test, $p<0.01$, Fig. 6d, e) and following IL-15 withdrawal from Stat5 DKI NK cells that were cultured in vitro with IL-15 (Grouped Multiple $t$-test, $p<0.01$, Fig. 6f, g). These data further establish the model that lower BCL2 expression in Stat5 DKI NK cells promotes caspase activation and the apoptosis/death of these cells.

\section{Discussion}

Formation of STAT1, STAT4 and STAT5 tetramers was demonstrated years ago ${ }^{5-8}$, but the in vivo roles of STAT tetramers were only recently elucidated, based on the analysis of 


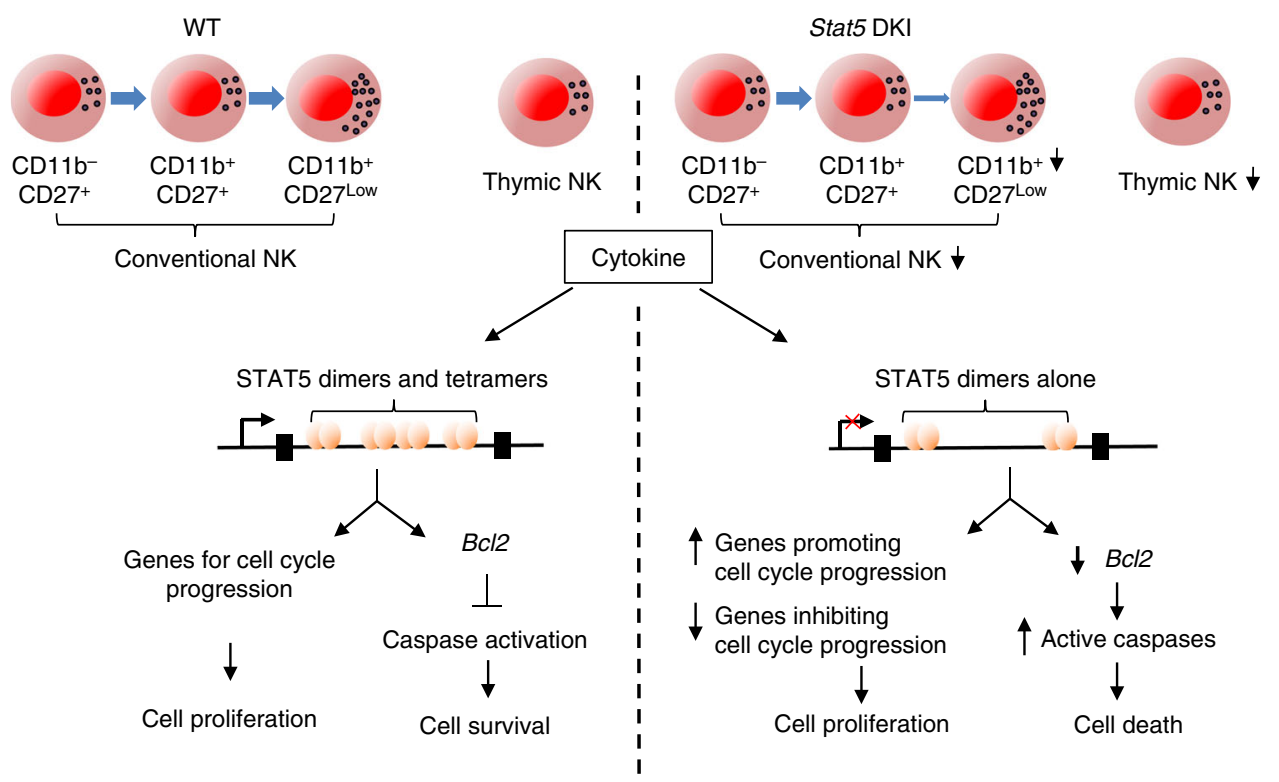

Fig. 7 Schematic of NK cell maturation, proliferation and survival in WT versus Stat5 DKI mice. WT mice (on the left) exhibit normal maturation, proliferation and survival of conventional NK cells and thymic NK cell cells. Stat5 DKI mice, which lack STAT5 tetramers (on the right), have defective NK cell maturation with decreased numbers of conventional NK cells as well as decreased numbers of thymic NK cells; their NK-cell proliferation is not defective, but $B C l 2$ expression is decreased and active caspases are increased, resulting in increased NK cell death

Stat5a and Stat5b $\mathrm{DKI}^{9}$ and Stat 1 knockin $(\mathrm{KI})^{49}$ mice, and recently a model of the three-dimensional structure of STAT5 tetramers was generated that helps to explain their observed binding preferences ${ }^{50}$. STAT5 tetramers are required for maintaining normal numbers of peripheral $\mathrm{CD} 8^{+} \mathrm{T}$ cells, $\mathrm{CD} 4^{+} \mathrm{CD} 25^{+}$ $\mathrm{T}$ cells, and NK cells, proliferative response of T cells to IL-2 or IL-15 stimulation, and T regulatory (Treg) cell function in vivo, but they are not required for viability, organ development, B cell development and function, or for the normal numbers of $\mathrm{CD} 4^{+}$ $\mathrm{T}$ cells ${ }^{9}$. In this study, we have demonstrated that STAT5 dimers are sufficient for early NK development, whereas STAT5 tetramers were required for later natural killer (NK) cell maturation (Fig. 7). Notably, in Stat5 DKI mice, the frequency of $\mathrm{CD} 11 \mathrm{~b}^{-} \mathrm{CD} 27^{+}$cells was increased, whereas the more mature

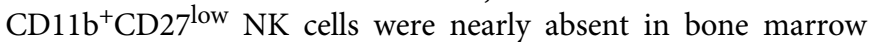
and significantly decreased in spleen. Analysis of RNA-Seq data from WT NK cells revealed that most of the genes known to be critical for NK cell development were expressed similarly during the $\mathrm{CD} 11 \mathrm{~b}^{-} \mathrm{CD} 27^{+}$to $\mathrm{CD} 11 \mathrm{~b}^{+} \mathrm{CD} 27^{+}$or $\mathrm{CD} 11 \mathrm{~b}^{+} \mathrm{CD} 27^{+}$to $\mathrm{CD} 11 \mathrm{~b}^{+} \mathrm{CD} 27^{\text {low }} \mathrm{NK}$ cell transitions, indicating their relatively constant expression during NK cell development. Interestingly, however, we identified 892 differentially expressed genes during the $\mathrm{CD} 11 \mathrm{~b}^{-} \mathrm{CD} 27^{+}$to $\mathrm{CD} 11 \mathrm{~b}^{+} \mathrm{CD} 27^{+}$and/or the $\mathrm{CD} 11 \mathrm{~b}^{+} \mathrm{CD} 27^{+}$ to $\mathrm{CD} 11 \mathrm{~b}^{+} \mathrm{CD} 27^{\text {low }} \mathrm{NK}$ cell transition, implicating them as playing roles in the NK cell maturation process. Among these differentially expressed genes, a subset had dysregulated expression in the corresponding subpopulations of Stat5 DKI NK cells. Interestingly, three genes (Mki67, Ccna2 and Ccnb2) that are involved in proliferation/cycling were downregulated in WT but not in Stat5 $\mathrm{CD} 11 \mathrm{~b}^{+} \mathrm{CD} 27^{\text {low }}$ NK cells.

In contrast to the defects in cell cycle progression of STAT5 tetramer-deficient $\mathrm{T}$ cells in response to high dose IL-2 or IL-15 stimulation in vitro or homoeostatic proliferation in vivo, STAT5 dimers were sufficient for cell cycle progression of NK cells in response to IL-2 or IL-15. In fact, Stat5 DKI NK cells exhibited slightly faster cell division in response to high doses of these cytokines, and these cells expressed more Ki67 $7^{+}$cells than did WT NK cells. Interestingly, as compared to WT NK cells, Stat5 DKI
NK cells had similar or increased expression levels of $C c n$ family genes, similar expression of most Cdk, Cdkn and Chek family genes (Supplementary Data 2b, c), but decreased expression of $C d k n 2 b, C d k n 1 a$ and Cish (Supplementary Data 2b). Thus, unlike their essential roles in IL-2-induced T-cell proliferation, STAT5 tetramers are not required for NK cell cycle progression.

Although Stat5 DKI CD8 ${ }^{+} \mathrm{T}$ cells ${ }^{9}$ and NK cells both exhibit increased cell death upon cytokine withdrawal, NK cells showed more rapid and enhanced death upon cytokine withdrawal, and this correlated with decreased expression of anti-apoptotic proteins in these cells (Fig. 7). Importantly, active caspases were also increased in Stat5 DKI NK cells, consistent with decreased expression of anti-apoptotic protein BCL2 triggering the activation of caspases, especially the initiator caspases, caspase-1 and caspase-9, which can then activate downstream effector molecules involved in cell death. Interestingly, in addition to the IL-15 $\rightarrow$ STAT5 $\rightarrow$ BCL2 survival pathway, it was reported that the IL-15 $\rightarrow$ ERK $\rightarrow$ FOXO3A pathway augments expression of MCL1, an anti-apoptotic BCL2 family protein, but diminishes expression of pro-apoptotic BIM (Bcl2l11) and NOXA (Pmaip1), which would promote the survival of WT NK cells ${ }^{51}$. Given that there is lower expression of Bcl2l11 mRNA in Stat 5 DKI NK cells (Supplementary Data 2a), similar expression of Mcl1 mRNA in Stat5 DKI and WT NK cells (Supplementary Data 2c), and very low expression of Pmaip1 (Reads Per Kilobase of transcript per Million mapped reads $<3$ ) in both WT and Stat5 DKI NK cells in response to IL-15 stimulation, MCL1, BIM, and NOXA do not appear to contribute to increased death in the Stat5 DKI NK cells. Instead, our data support the concept that the absence of STAT5 tetramers lowers survival primarily due to diminished BCL2 and augmented caspase activity.

Interestingly, STAT5 tetramer formation was reported to be associated with leukaemogenesis in a mouse model ${ }^{52}$. However, a caveat is that the study was performed in part with the STAT5A W37A mutant, which initially was reported to be important for tetramerization ${ }^{7}$ but then was shown to affect stability of the protein rather than tetramer formation ${ }^{6}$. Thus, further work is needed to better define the potential relationship of STAT5 
tetramers to leukaemogenesis. Our Stat5 DKI mice may allow one to better evaluate the funcitons of STAT5 tetramers in the development of leukaemia.

In summary, our data underscore non-redundant roles of STAT5 dimers and tetramers in the development, maturation, survival, and expansion of mouse NK cells, with STAT5 dimers being critical for early development of conventional NK cells and their expansion in vitro, whereas STAT5 tetramers are essential for later NK maturation, expansion at lower concentration of the cytokines, and survival, providing an explanation for the lower NK cell numbers in Stat5 DKI mice. We demonstrate that STAT5 tetramers are required for normal $B c l 2$ expression, with little if any IL-15-induced expression of Bcl2 in Stat5 DKI NK cells. Moreover, the lack of STAT5 tetramers is associated with the activation of caspases to initiate the cascade for apoptosis/cell death, underscoring the role of STAT5 tetramers in the survival as well as the maturation of NK cells. Finally, our study also implies that mutation(s) of the STAT5 N-domain that diminish or abolish tetramer formation may result in NK cells deficiency, and interfering with tetramer formation by small molecule inhibitors could potentially be a mechanism for controlling NK cell numbers in NK leukaemia.

\section{Methods}

Mice. Stat 5 DKI mice were described previously ${ }^{9}$. Both female and male mice from 8 to 20 -weeks old were used for the experiments. The mice were housed in specific pathogen-free mouse facilities at National Institutes of Health (NIH) Bethesda campus. All mouse protocols were approved by the National Heart, Lung and Blood Institute Animal Care Use Committee, and experiments followed NIH guidelines for using animals in intramural research.

Flow cytometric analyses. For cell surface marker staining, $10^{6}$ cells in $100 \mu \mathrm{l}$ PBS containing $0.5 \%$ BSA and $0.1 \%$ sodium azide were stained with $0.5 \mu \mathrm{g}$ of fluorescent-labelled monoclonal antibodies (BD Biosciences, San Jose, CA or BioLegend Inc., San Diego, CA) for CD3 (145-2C11), CD122 (TM- $\beta 1$, IL-2R $\beta$ ), NK1.1 (PK136), CD11b (M1/70), CD27 (LG.3A10), CD49b (DX5), Ly49A (A1), Ly49H (3D10); for detection of apoptosis, the cells were additionally stained with Annexin V ( $5 \mu$ l per sample), 7AAD ( $5 \mu$ l per sample); for BCL2 expression, after fixation and permibilization the cells were stained with $20 \mu \mathrm{l}$ of FITC- or PElabelled hamster anti-mouse BCL2 Set (3F11, BD Biosciences); for exclusion of linage-positive populations, $10^{6}$ cells were first stained with $0.5 \mu \mathrm{g}$ of biotin-labelled antibodies (BioLegend) for TCR $\beta$ (H57-597), CD3 (145-2C11), CD4 (H129.19), CD8a (53-6.7), CD19 (1D3), IgM (RMM-1), Ter119 (Ter119), and then with $0.125 \mu \mathrm{g}$ fluorescent-labelled streptavidin (BioLegend).

To measure caspase activity in the cells, total splenocytes were incubated at $37^{\circ} \mathrm{C}$ for $1 \mathrm{~h}$ with fluorescent-labelled caspase inhibitor FAM-VAD-FMK probes (FLICA reagent) for Poly caspases (91), caspase-1 (97), caspases-3, 7 (93), and caspase-9 (912) according to the manufacturer's instructions (Immunochemistry Technologies, Bloomington, MN, USA). Data were acquired using a FACSCanto II flow cytometer (BD Immunocytometry Systems) and analysed using FlowJo (v9.7.5, Tree Star, Inc., Ashland, OR).

Cell sorting and RNA isolation. To sort splenic NK subpopulations, total splenocytes were isolated from $10 \mathrm{WT}$ or 15 Stat5 DKI female mice and total NK cells were enriched via negative selection using antibodies $\left(0.5 \mu \mathrm{g}\right.$ per $10^{6}$ cells $)$ for IgM, CD19, TCR $\beta$, CD3, CD4, CD8, Ter119 (Biolegend) and Dynabeads Sheep anti-Rat IgG $\left(2.5 \mu \mathrm{l}\right.$ per $10^{6}$ cells, Invitrogen, Grand Island, NY). CD3 ${ }^{-} \mathrm{CD} 122^{+} \mathrm{NK} 1.1^{+}$ NK cells were then sorted on a FACSAriaII cell sorter for CD11b $\mathrm{C}^{-} \mathrm{CD} 27^{+}$

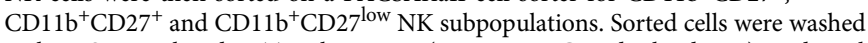
with PBS once, lyzed in Trizol Reagent (Invitrogen, Grand Island, NY), and total RNA was isolated using Direct-zol RNA MiniPrep Kit (R2050, Zymo Research, Irvine, CA).

\section{Cell proliferation and survival assays. To monitor cell division, 20 million} splenic or bone marrow cells from WT or Stat5 DKI mice were labelled in $1 \mathrm{ml}$ of PBS with $2.5 \mu \mathrm{M}$ of CFSE (CellTracer CFSE Cell Proliferation Kit, Invitrogen, Carlsbad, CA) at room temperature for $7 \mathrm{~min}$, washed once with serum and twice with complete RPMI-1640 medium, $1.5 \times 10^{6} \mathrm{ml}^{-1}$ CFSE-labelled cells were then cultured in the presence of $20 \mathrm{ng} \mathrm{ml}^{-1}$ recombinant human IL-15 (R\&D Systems, Minneapolis MN or BioLegend), and fresh rhIL-15 was added every 2 days. NK cell division was monitored for CFSE dilution using flow cytometry on day 2, 3 and 4 by staining cells with fluorescent-labelled antibodies for CD3, CD122 and NK1.1.

To determine cell viability after IL-15 withdrawal, column purified (Miltenyi Biotec Inc., San Diego, CA) NK cells from WT or Stat5 DKI mice were cultured in complete RPMI-1640 medium supplemented with $20 \mathrm{ng} \mathrm{ml}^{-1}$ rhIL-15 for 6-7 days fresh rhIL-15 was added every 2 days, cells were then washed three times with complete medium, cultured in complete medium without IL-15, stained at the indicated time points, and viable NK cells were determined as $\mathrm{CD}^{-} \mathrm{CD} 122^{+}$ $\mathrm{NK} 1.1^{+}$Annexin $\mathrm{V}^{-} 7 \mathrm{AAD}^{-}$. Annexin $\mathrm{V}^{+} 7 \mathrm{AAD}^{-}$cells were scored as apoptotic cells and Annexin $\mathrm{V}^{+} 7 \mathrm{AAD}^{+}$as dead cells.

Cell cytotoxicity assays. For in vitro NK cell cytotoxicity assays, splenic NK cells from 3 of WT and Stat5 DKI mice were enriched using NK cell negative selection kit (Miltenyi Biotech, San Diego, CA) and cultured with $20 \mathrm{ng} \mathrm{ml}^{-1}$ rhIL-15 (R\&D) for 6 days to reach similarly high purity of NK cells, incubated at indicated ratio in triplicates with ${ }^{51} \mathrm{Cr}$-labelled YAC-1 cells at $37^{\circ} \mathrm{C}$ for $4 \mathrm{~h}$. Specific target (YAC-1) cell lysis was calculated.

For in vivo NK cell cytotoxicity assays, $\mathrm{H} 2$ class I gene-deficient RMA-S and H2 class I gene expressing RMA cells (provided by Dr. Lewis L. Lanier, University of Califonia, San Francisco) were labelled by 0.5 and $5 \mu \mathrm{M}$ of CFSE, respectively, equal number of the labelled RMA-S and RMA cells were mixed, and $2 \times 10^{6}$ cells were intraperitoneally injected into each of WT and Stat5 DKI mice. Peritoneal cells were recovered $16 \mathrm{~h}$ after injection and the recovery rate of each cell types was determined by flow cytometry.

Tumour rejection experiments. RMA-S cells were cultured in complete RPMI1640 medium supplemented with $50 \mu \mathrm{M} \beta$-mercaptoenthol. For tumour rejection experiments, the cells were washed with PBS 3 times, resuspended in PBS, and $2 \times$ $10^{5}$ cells in $150 \mu \mathrm{l}$ PBS were subcutaneously injected into the scruff of the neck of each mouse. Tumour size was measured using a digital caliper daily 7 days after injection. Animals were killed when the tumour reached $20 \mathrm{~mm}$ in diameter or showed severe ulceration.

RNA-Seq library preparation and sequencing. Libraries were prepared using 150 ng of total RNA from bone marrow NK cells and splenic NK subpopulations and KAPA Stranded RNA-Seq Library Preparation Kit (KK8400, KAPA Biosystems, Wilmington, MA), and each library was indexed using NEXflex DNA Barcodes-24 (NOVA-514103, BIOO Scientific, Austin, TX). Barcoded PCR products were purified on $2 \% \mathrm{E}-\mathrm{Gel}, 250-400 \mathrm{bp}$ fragments were purified, quantified on Qbit (Invitrogen), mixed, and sequenced on an Illumina HiSeq 2500 or HiSeq 3000 platform (Illumina, San Diego, CA).

ChIP-Seq library preparation and sequencing. Splenic NK cells from $10 \mathrm{WT}$ and 13 Stat5 DKI mice were purified (Miltenyi Biotec Inc.), expanded in vitro with $20 \mathrm{ng} \mathrm{ml}^{-1}$ of human recombinant IL-15 (R\&D Systems or BioLegend) for 10 days, with fresh rhIL-15 being added every two days, yielding 50-80 million of nearly $100 \%$ pure $\mathrm{CD}^{-} \mathrm{CD} 122^{+} \mathrm{NK} 1.1^{+}$cells. The cells were washed three times with medium, rested in complete RPMI-1640 medium without IL-15 for $2 \mathrm{~h}$, not treated or treated with $40 \mathrm{ng} \mathrm{ml}^{-1}$ of IL-15 for $1 \mathrm{~h}$, and cross-linked with $1 \%$ formaldehyde (methanol-free, Pierce, Rockford, IL) at room temperature for $10 \mathrm{~min}$. After sonication, fragmented chromatin equivalent to 10 million cells were immunoprecipitated with control rabbit IgG (sc-3888, Santa Cruz Biotechnology, Dallas TX) or anti-STAT5B (AF1584, R\&D Systems) and Magna ChIP Protein A + G Magnetic Beads (16-663, Millipore, Billerica MA). ChIP-Seq DNA libraries were prepared using KAPA LTP Library Preparation Kit (KK8232, Kapa Biosystems, Wilmington, MA) and NEXflex DNA Barcodes-24 (NOVA-514103, BIOO Scientific, Austin, TX), and the libraries were then sequenced on an Illumina HiSeq 3000 platform.

RNA-seq analysis. Sequenced reads (50 bp, single end) were obtained with the Illumina CASAVA pipeline and mapped to the mouse genome (mm9/NCBI37) using TopHat 2.0.11. Only uniquely mapped reads were retained. RefSeq gene database was downloaded from the UCSC genome browser for RNA-Seq analysis Raw counts that fell on exons of each gene were calculated and normalised to obtain RPKM (Reads Per Kilobase per Million mapped reads) values. Differentially expressed genes were identified based on indicated RPKM and fold change thresholds. The expression heatmaps were generated with the "pheatmap" library in R using the scale = "row" parameter. Scatter plots are generated by DataGraph 4.1 (Visual Data Tools, Inc.)

ChIP-seq analysis. Sequenced reads were aligned to the mouse genome (mm9/ NCBI37) using Bowtie 0.12.9. Only uniquely mapped reads were retained. Normalised read counts were summed in $20 \mathrm{bp}$ sliding windows and displayed in the Integrative Genomics Viewer (IGV). MACS 1.4.2 was used to call binding sites (peaks) relative to control libraries. The $p$-value threshold was set as $1 \times 10^{-5}$, and the effective genome size was set as $2.7 \times 10^{9}$. Transcription factor was considered as 'bound' to genes if peaks were within $5 \mathrm{~kb}$ upstream of the transcription start site and anywhere across the gene body.

To compute STAT5B binding profiles in T and NK cells, we chose $\pm 3 \mathrm{~kb}$ regions around combined peak summits and divided the regions into bins of 20-bp windows. Reads (or tags) that fell into each bin were counted and normalised by library size. Heatmaps of binding profiles were generated based on K-means 
clustering and plotted using seqMiner 1.3.3. STAT5 dimer and tetramer motifs were identified as described previously ${ }^{9}$.

Statistical analysis. Statistical analyses were performed by grouped multiple $t$-test analysis using Prism 7.0b (GraphPad Software, Inc., La Jolla, CA), error bars are means \pm SEM; ${ }^{* * * *} p<0.0001 ;{ }^{* * *} p<0.001,{ }^{* *} p<0.01 ;{ }^{*} p<0.05$; NS, $p>0.05$.

Data availability. ChIP-Seq and RNA-Seq data have been deposited in the National Center for Biotechnology Information Gene Expression Omnibus (GEO) database (https://www.ncbi.nlm.nih.gov/geo) under the GEO Series accession numbers GSE101470 and GSE36890. All other materials are available from the corresponding authors on request.

Received: 20 February 2017 Accepted: 20 September 2017 Published online: 06 November 2017

\section{References}

1. Leonard, W. J. \& O'Shea, J. J. Jaks and STATs: biological implications. Аnnu. Rev. Immunol. 16, 293-322 (1998).

2. Stark, G. R. \& Darnell, J. E. Jr. The JAK-STAT pathway at twenty. Immunity 36, 503-514 (2012)

3. Rochman, Y., Spolski, R. \& Leonard, W. J. New insights into the regulation of T cells by gamma(c) family cytokines. Nat. Rev. Immunol. 9, 480-490 (2009).

4. John, S., Vinkemeier, U., Soldaini, E., Darnell, J. E. Jr. \& Leonard, W. J. The significance of tetramerization in promoter recruitment by Stat5. Mol. Cell Biol. 19, 1910-1918 (1999).

5. Soldaini, E. et al. DNA binding site selection of dimeric and tetrameric Stat5 proteins reveals a large repertoire of divergent tetrameric Stat5a binding sites. Mol. Cell Biol. 20, 389-401 (2000).

6. Chen, X. et al. A reinterpretation of the dimerization interface of the Nterminal domains of STATs. Protein Sci. 12, 361-365 (2003).

7. Vinkemeier, U., Moarefi, I., Darnell, J. E. Jr \& Kuriyan, J. Structure of the amino-terminal protein interaction domain of STAT-4. Science 279, 1048-1052 (1998).

8. Xu, X., Sun, Y. L. \& Hoey, T. Cooperative DNA binding and sequence-selective recognition conferred by the STAT amino-terminal domain. Science 273, 794-797 (1996).

9. Lin, J. X. et al. Critical role of STAT5 transcription factor tetramerization for cytokine responses and normal immune function. Immunity. 36, 586-599 (2012).

10. Yao, Z. et al. Stat5a/b are essential for normal lymphoid development and differentiation. Proc. Natl Acad. Sci. USA 103, 1000-1005 (2006).

11. Di Santo, J. P. Natural killer cell developmental pathways: a question of balance. Annu. Rev. Immunol. 24, 257-286 (2006).

12. Yokoyama, W. M., Kim, S. \& French, A. R. The dynamic life of natural killer cells. Annu. Rev. Immunol. 22, 405-429 (2004).

13. Vivier, E. et al. Innate or adaptive immunity? The example of natural killer cells. Science 331, 44-49 (2011)

14. Lanier, L. L. Evolutionary struggles between NK cells and viruses. Nat. Rev. Immunol. 8, 259-268 (2008).

15. Yokoyama, W. M. Mistaken notions about natural killer cells. Nat. Immunol. 9 , 481-485 (2008)

16. Cooper, M. A., Colonna, M. \& Yokoyama, W. M. Hidden talents of natural killers: NK cells in innate and adaptive immunity. EMBO Rep. 10, 1103-1110 (2009).

17. Waldmann, T. A. \& Tagaya, Y. The multifaceted regulation of interleukin-15 expression and the role of this cytokine in NK cell differentiation and host response to intracellular pathogens. Annu. Rev. Immunol. 17, 19-49 (1999).

18. Giri, J. G. et al. Identification and cloning of a novel IL-15 binding protein that is structurally related to the alpha chain of the IL-2 receptor. $E M B O \mathrm{~J} . \mathbf{1 4}$, 3654-3663 (1995).

19. Dubois, S., Mariner, J., Waldmann, T. A. \& Tagaya, Y. IL-15Ralpha recycles and presents IL-15 In trans to neighboring cells. Immunity 17, 537-547 (2002).

20. Lodolce, J. P., Burkett, P. R., Boone, D. L., Chien, M. \& Ma, A. T cellindependent interleukin 15Ralpha signals are required for bystander proliferation. J. Exp. Med. 194, 1187-1194 (2001).

21. Giri, J. G. et al. Utilization of the beta and gamma chains of the IL-2 receptor by the novel cytokine IL-15. EMBO J. 13, 2822-2830 (1994).

22. Bamford, R. N. et al. The interleukin (IL) 2 receptor beta chain is shared by IL-2 and a cytokine, provisionally designated IL-T, that stimulates T-cell proliferation and the induction of lymphokine-activated killer cells. Proc. Natl Acad. Sci. USA 91, 4940-4944 (1994).
23. Carson, W. E. et al. A potential role for interleukin- 15 in the regulation of human natural killer cell survival. J. Clin. Invest. 99, 937-943 (1997).

24. Kennedy, M. K. et al. Reversible defects in natural killer and memory CD8 $\mathrm{T}$ cell lineages in interleukin $15^{-}$deficient mice. J. Exp. Med. 191, 771-780 (2000).

25. Lodolce, J. P. et al. IL-15 receptor maintains lymphoid homeostasis by supporting lymphocyte homing and proliferation. Immunity 9, 669-676 (1998).

26. Imada, K. et al. Stat5b is essential for natural killer cell-mediated proliferation and cytolytic activity. J. Exp. Med. 188, 2067-2074 (1998).

27. Chiossone, L. et al. Maturation of mouse NK cells is a 4 -stage developmental program. Blood 113, 5488-5496 (2009).

28. Fathman, J. W. et al. Identification of the earliest natural killer cell-committed progenitor in murine bone marrow. Blood 118, 5439-5447 (2011).

29. Hayakawa, Y. \& Smyth, M. J. CD27 dissects mature NK cells into two subsets with distinct responsiveness and migratory capacity. J. Immunol. 176 1517-1524 (2006).

30. Lin, J. X. et al. The role of shared receptor motifs and common Stat proteins in the generation of cytokine pleiotropy and redundancy by IL-2, IL-4, IL-7, IL-13, and IL-15. Immunity 2, 331-339 (1995).

31. Vosshenrich, C. A. et al. A thymic pathway of mouse natural killer cell development characterized by expression of GATA-3 and CD127. Nat. Immunol. 7, 1217-1224 (2006).

32. Barton, K. et al. The Ets-1 transcription factor is required for the development of natural killer cells in mice. Immunity 9, 555-563 (1998).

33. Ramirez, K. et al. Gene deregulation and chronic activation in natural killer cells deficient in the transcription factor ETS1. Immunity 36, 921-932 (2012).

34. Gordon, S. M. et al. The transcription factors T-bet and Eomes control key checkpoints of natural killer cell maturation. Immunity 36, 55-67 (2012).

35. Yokota, Y. et al. Development of peripheral lymphoid organs and natural killer cells depends on the helix-loop-helix inhibitor Id2. Nature 397, 702-706 (1999).

36. Ogasawara, K. et al. Requirement for IRF-1 in the microenvironment supporting development of natural killer cells. Nature 391, 700-703 (1998).

37. Taki, S., Nakajima, S., Ichikawa, E., Saito, T. \& Hida, S. IFN regulatory factor-2 deficiency revealed a novel checkpoint critical for the generation of peripheral NK cells. J. Immunol. 174, 6005-6012 (2005).

38. Aliahmad, P., de la Torre, B. \& Kaye, J. Shared dependence on the DNAbinding factor TOX for the development of lymphoid tissue-inducer cell and NK cell lineages. Nat. Immunol. 11, 945-952 (2010).

39. Lacorazza, H. D. et al. The ETS protein MEF plays a critical role in perforin gene expression and the development of natural killer and NK-T cells. Immunity 17, 437-449 (2002).

40. Suzuki, H., Duncan, G. S., Takimoto, H. \& Mak, T. W. Abnormal development of intestinal intraepithelial lymphocytes and peripheral natural killer cells in mice lacking the IL-2 receptor beta chain. J. Exp. Med. 185, 499-505 (1997).

41. Vosshenrich, C. A. et al. Roles for common cytokine receptor gamma-chaindependent cytokines in the generation, differentiation, and maturation of NK cell precursors and peripheral NK cells in vivo. J. Immunol. 174, 1213-1221 (2005).

42. Park, S. Y. et al. Developmental defects of lymphoid cells in Jak3 kinasedeficient mice. Immunity 3, 771-782 (1995).

43. Cao, X. et al. Defective lymphoid development in mice lacking expression of the common cytokine receptor gamma chain. Immunity 2, 223-238 (1995).

44. DiSanto, J. P., Muller, W., Guy-Grand, D., Fischer, A. \& Rajewsky, K. Lymphoid development in mice with a targeted deletion of the interleukin 2 receptor gamma chain. Proc. Natl Acad. Sci. USA 92, 377-381 (1995).

45. Karre, K., Ljunggren, H. G., Piontek, G. \& Kiessling, R. Selective rejection of H2-deficient lymphoma variants suggests alternative immune defence strategy. Nature 319, 675-678 (1986).

46. Delconte, R. B. et al. CIS is a potent checkpoint in NK cell-mediated tumor immunity. Nat. Immunol. 17, 816-824 (2016).

47. Creagh, E. M. Caspase crosstalk: integration of apoptotic and innate immune signalling pathways. Trends Immunol. 35, 631-640 (2014).

48. Czabotar, P. E., Lessene, G., Strasser, A. \& Adams, J. M. Control of apoptosis by the BCL-2 protein family: implications for physiology and therapy. Nat. Rev. Mol. Cell Biol. 15, 49-63 (2014).

49. Begitt, A. et al. STAT1-cooperative DNA binding distinguishes type 1 from type 2 interferon signaling. Nat. Immunol. 15, 168-176 (2014).

50. Sathyanarayana, B. K., Li, P., Lin, J. X., Leonard, W. J. \& Lee, B. Molecular Models of STAT5A tetramers complexed to DNA predict relative genome-wide frequencies of the spacing between the two dimer binding motifs of the tetramer binding sites. PLOS ONE 11, e0160339 (2016). 
51. Huntington, N. D. et al. Interleukin 15-mediated survival of natural killer cells is determined by interactions among Bim, Noxa and Mcl-1. Nat. Immunol. 8, 856-863 (2007).

52. Moriggl, R. et al. Stat5 tetramer formation is associated with leukemogenesis. Cancer Cell 7, 87-99 (2005).

\section{Acknowledgements}

This work was funded by the Division of Intramural Research, National Heart, Lung, and Blood Institute, National Institutes of Health. We thank Dr Eric O. Long,

National Institute of Allergy and Infectious Diseases, NIH for critical comments, and Dr Lewis L. Lanier, UCSF for RMA and RMA-S cells. Next generation sequencing was performed in the NHLBI DNA Sequencing Core, and cell sorting was performed in the NHLBI Flow Cytometry Core.

\section{Author contributions}

J.-X.L., N.D., R.S. and T.G. conducted experiments and analysed data. P.L. and M.K. analysed ChIP-Seq and RNA-Seq data. J.-X.L. and W.J.L. conceived the project, supervised the research and wrote the manuscript with input and editing from all the authors.

\section{Additional information}

Supplementary Information accompanies this paper at doi:10.1038/s41467-017-01477-5.
Competing interests: The authors declare no competing financial interests.

Reprints and permission information is available online at http://npg.nature.com/ reprintsandpermissions/

Publisher's note: Springer Nature remains neutral with regard to jurisdictional claims in published maps and institutional affiliations.

(c) (i) Open Access This article is licensed under a Creative Commons Attribution 4.0 International License, which permits use, sharing, adaptation, distribution and reproduction in any medium or format, as long as you give appropriate credit to the original author(s) and the source, provide a link to the Creative Commons license, and indicate if changes were made. The images or other third party material in this article are included in the article's Creative Commons license, unless indicated otherwise in a credit line to the material. If material is not included in the article's Creative Commons license and your intended use is not permitted by statutory regulation or exceeds the permitted use, you will need to obtain permission directly from the copyright holder. To view a copy of this license, visit http://creativecommons.org/ licenses/by/4.0/.

(C) The Author(s) 2017 